\title{
Diagnosis of airway obstruction in the elderly: contribution of the SARA study
}

This article was published in the following Dove Press journal:

International Journal of COPD

26 June 2012

Number of times this article has been viewed

\section{Claudio Sorino ${ }^{1,2}$ \\ Salvatore Battaglia' \\ Nicola Scichilone' \\ Claudio Pedone ${ }^{3}$ \\ Raffaele Antonelli-Incalzi ${ }^{3}$ \\ Duane Sherrill ${ }^{4}$ \\ Vincenzo Bellia' \\ 'Biomedical Department of Internal and Specialist Medicine, Section of Pulmonology, University of Palermo, Italy; ${ }^{2}$ Division of Pulmonology, S Anna Hospital, Como, Italy; ${ }^{3}$ Chair of Geriatrics, University Campus Bio-Medico, Roma, Italy; ${ }^{4} \mathrm{Mel}$ and Enid Zuckerman College of Public Health, University of Arizona, Tucson, AZ, USA}

Correspondence: Claudio Sorino University of Palermo,

via Trabucco 180, 90I46 Palermo, Italy

Tel +39329408 I729

Fax +39 9| 6891857

Email claudiosorino@libero.it
Background: The choice between lower limit of normal or fixed value of forced expiratory volume in one second/forced vital capacity ratio $\left(\mathrm{FEV}_{1} / \mathrm{FVC}\right)<0.70$ as the criterion for confirming airway obstruction is an open issue. In this study, we compared the criteria of lower limit of normal and fixed $\mathrm{FEV}_{1} / \mathrm{FVC}$ for diagnosis of airway obstruction, with a focus on healthy elderly people.

Methods: We selected 367 healthy nonsmoking subjects aged 65-93 years from 1971 participants in the population-based SARA (Salute Respiratoria nell'Anziano, Italian for "Respiratory Health in the Elderly") study, analyzed their spirometric data, and tested the relationship between spirometric indices and anthropometric variables. The lower limit of normal for $\mathrm{FEV}_{1} / \mathrm{FVC}$ was calculated as the fifth percentile of the normal distribution for selected subjects.

Results: While $\mathrm{FEV}_{1}$ and FVC decreased significantly with aging, the relationship between $\mathrm{FEV}_{1} / \mathrm{FVC}$ and age was not statistically significant in men or women. The lower limit of normal for $\mathrm{FEV}_{1} / \mathrm{FVC}$ was 0.65 in men and 0.67 in women. Fifty-five participants $(15 \%)$ had $\mathrm{FEV}_{1} /$ FVC $<0.70$ and would have been inappropriately classified as obstructed according to the Global Initiative for Obstructive Lung Disease, American Thoracic Society/European Respiratory Society, and Canadian guidelines on chronic obstructive pulmonary disease. By applying different $\mathrm{FEV}_{1} / \mathrm{FVC}$ thresholds for the different age groups, as previously proposed in the literature, ( 0.70 for $<70$ years, 0.65 for $70-80$ years, and 0.60 for $>80$ years) the percentage of patients classified as obstructed decreased to $6 \%$. No subjects older than 80 years had an $\mathrm{FEV}_{1} / \mathrm{FVC}<0.60$.

Conclusion: The present results confirm the inadequacy of $\mathrm{FEV}_{1} / \mathrm{FVC}<0.70$ as a diagnostic criterion for airway obstruction after the age of 65 years. $\mathrm{FEV}_{1} / \mathrm{FVC}<0.65$ and $<0.67$ (for men and women, respectively) could identify subjects with airway obstruction in such a population. Further reduction of the threshold after 80 years is not justified.

Keywords: aging, airflow obstruction, chronic obstructive pulmonary disease, forced expiratory volume, lung function tests, spirometry

\section{Introduction}

The most appropriate way to diagnose airway obstruction is currently the subject of heated debate. ${ }^{1-10}$ Most national and international chronic obstructive pulmonary disease (COPD) guidelines recommend to use a forced expiratory volume in one second/forced vital capacity ratio $\left(\mathrm{FEV}_{1} / \mathrm{FVC}\right)$ of 0.70 as a suitable threshold value to define the presence of an obstructive ventilatory defect. Commonly used guidelines include those of the Global Initiative for Obstructive Lung Disease (GOLD), ${ }^{11}$ the American Thoracic Society/European Respiratory Society, ${ }^{12}$ the British Thoracic 
Society, ${ }^{13}$ the Canadian Thoracic Society, ${ }^{14}$ and the National Institute for Health and Clinical Excellence. ${ }^{15}$

However, there is evidence that the fixed cut-off value of 0.70 for $\mathrm{FEV}_{1} / \mathrm{FVC}$ becomes less specific in males aged $>40$ years and females $>50$ years, implying a risk of overestimation of airway obstruction. This is due to an age-related decline in pulmonary volumes, particularly in $\mathrm{FEV}_{1}$, which is observed even in healthy people with no history of exposure to noxious particles or gases. ${ }^{16-19}$ Proposed strategies for reducing the misclassification of airway obstruction include use of the lower limit of normal for $\mathrm{FEV}_{1} / \mathrm{FVC}$, calculated as the fifth percentile of the normal distribution in a healthy population, ${ }^{20-22}$ or the use of different $\mathrm{FEV}_{1} / \mathrm{FVC}$ thresholds for different age groups (eg, 0.70 for subjects aged $<70$ years, 0.65 for those aged $70-80$ years, and 0.60 for those aged $>80$ years). ${ }^{19}$

On this basis, a group of colleagues involved in respiratory research and/or the diagnosis and treatment of lung diseases recently wrote an open letter to members of the GOLD committee inviting them to change the method by which airway obstruction is defined and asking for retraction of the fixed ratio in favor of the lower limit of normal. ${ }^{1}$

The aim of the present study was to provide additional information for determination of the most appropriate spirometric criteria for confirming airway obstruction in the elderly, by describing lung function and calculating the lower limit of normal for $\mathrm{FEV}_{1} / \mathrm{FVC}$ in healthy nonsmoking elderly subjects (age $>65$ years) who participated in the Italian multicenter SARA (acronym of Salute Respiratoria nell'Anziano, Italian for "Respiratory Health in the Elderly") study. The degree of potential misclassification relative to use of 0.70 or other proposed fixed thresholds for $\mathrm{FEV}_{1} / \mathrm{FVC}$ was also evaluated.

\section{Materials and methods}

We performed a cross-sectional analysis of data from the SARA study, the design of which, along with technical characteristics of instruments as well as training of operators and results of quality control of spirometry, have been described in detail elsewhere. ${ }^{23}$ Briefly, the study involved 24 pulmonary or geriatric institutions distributed throughout Italy. A total of 1971 subjects aged 65-100 years were recruited as consecutive outpatients referred between January 1996 and December 1997 to the participating centers (see Appendix). The study design was approved by the ethics committee of the University of Palermo. Patients gave their written consent to participate in the study.

Lung function was measured using an identical fully computerized water-sealed Stead-Wells spirometer
(Baires System, Biomedin, Padua, Italy) by specifically trained and certified personnel supervised by a rigorous real-time control of acceptability and repeatability ${ }^{23}$ according to American Thoracic Society recommendations. ${ }^{24} \mathrm{FVC}$ maneuvers were performed with the patient sitting. The largest $\mathrm{FVC}$ and $\mathrm{FEV}_{1}$ were selected from a minimum of two acceptable tests. The $\mathrm{FEV}_{1} / \mathrm{FVC}$ ratio was calculated on the basis of the highest values of individual parameters obtained in the acceptable curves for each subject. Analyses were conducted only on patients with good repeatability of the above-mentioned indices (difference between two best values $<150 \mathrm{~mL}$ ). ${ }^{25}$

Of the 1870 subjects who performed spirometry, we selected only those without any previous or present diagnosis or any sign or symptom suggestive of respiratory diseases according to the modified International Union against Tuberculosis and Lung Disease bronchial symptoms questionnaire. ${ }^{25,26}$ Current smokers and previous smokers with a smoking exposure $>5$ pack/year were excluded, since the $<5$ pack/year smoking exposure was not significantly associated with decreased lung function. ${ }^{27}$ Additional exclusion criteria were: severe hepatic failure; severe renal failure; severe cardiac failure; cognitive and/or sensory impairment severe enough to affect a multidimensional assessment; severe kyphoscoliosis with occiput wall distance (distance between the occiput and the wall when the patient stands with heels and shoulder against the wall with the back straight) $>10$; occurrence of a major psychosocial event (eg, bereavement) within the past 6 months; and hospitalization for any reason within the past 6 months. We further excluded individuals who had hypertension (diastolic pressure $\geq 90 \mathrm{mmHg}$ and/or systolic pressure $\geq 160 \mathrm{mmHg}$ ), diabetes, and/or major electrocardiographic abnormalities.

Statistical analyses were performed using SPSS (SPSS Inc, Chicago, IL) and Stata (Stata Corporation, College Station, TX) software packages. Regression models were used for testing the relationship between spirometric indices and anthropometric variables. Based on the recommendations from the American Thoracic Society/European Respiratory Society task force, ${ }^{22}$ the lower limit of normal for $\mathrm{FEV}_{1} / \mathrm{FVC}$ was estimated as the fifth percentile of its frequency distribution. To evaluate the effect of aging on spirometric measures independently of body height, $\mathrm{FEV}_{1}$ and $\mathrm{FVC}$ were normalized for height at the third power. ${ }^{28,29}$

\section{Results}

After applying the above-mentioned selection criteria, our final data set consisted of 367 healthy, nonsmoking subjects. 
One hundred and one subjects were excluded for lack of availability of lung function testing, a further 709 subjects because of a history of respiratory disease, 445 for significant smoking exposure ( $>5$ pack/year), 262 for inadequate quality of spirometry, and 87 for the above-mentioned additional exclusion criteria.

Tables 1 and 2 show anthropometric and functional data for the sample and distribution of the participants according to age and gender. Although the most advanced ages were less represented, a total of 73 subjects aged 80 years and over were included. The sample consisted of 314 never-smokers $(85.6 \%)$ and 53 former-smokers with a smoking exposure from 0.15 to 5 pack-years (mean \pm standard deviation, $2.75 \pm 1.5$ ).

As shown in Figure 1, the values of $\mathrm{FEV}_{1} / \mathrm{FVC}$ showed a normal frequency distribution. The mean $\mathrm{FEV}_{1} / \mathrm{FVC}$ was $0.75 \pm 0.6$ in males and $0.78 \pm 0.6$ in females, whereas the corresponding fifth percentiles were 0.65 and 0.67 , respectively, in males and females. $\mathrm{FEV}_{1}$ and FVC significantly decreased with age $(\mathrm{r}=-0.38$ and $-0.35 ; P<0.001)$, while $\mathrm{FEV}_{1} / \mathrm{FVC}$, was not significantly correlated with age or height in either gender group over the considered range of age (lowest $P=0.103$ ). As a consequence, there was no rationale to develop reference equations for $\mathrm{FEV}_{1} / \mathrm{FVC}$, with age or height as independent variables in this restricted range of age. Figure 2 shows the decline in $\mathrm{FEV}_{1}$ and $\mathrm{FVC}$ with increasing age observed in the study sample in men and women, after normalization for height.

In the sample of healthy subjects, $15 \%$ had a $\mathrm{FEV}_{1} /$ $\mathrm{FVC}<0.70$, and would have been inappropriately classified as obstructed according to GOLD criteria. Table 3 describes the proportion of participants with the ratio $<70$ in the different age groups. By applying the $\mathrm{FEV}_{1} / \mathrm{FVC}$ thresholds proposed by Hardie et $\mathrm{al}^{19}$ for different age groups (ie, 0.70 for $<70$ years, 0.65 for $70-80$ years, and 0.60 for $>80$ years), the percentage of obstructed subjects decreased to $6 \%$ (men $11 \%$, women $4 \%$ ). In particular, the proportion of subjects

Table I Anthropometric and functional characteristics of the study sample, with data expressed as the mean \pm standard deviation

\begin{tabular}{lcc}
\hline & Women & Men \\
\hline Age, years & $73.3 \pm 6.2$ & $74.2 \pm 6.9$ \\
Height, cm & $154.8 \pm 7.0$ & $167.8 \pm 6.4$ \\
Weight, kg & $63.1 \pm 11.2$ & $73.7 \pm 11.2$ \\
FEV, $\mathrm{mL}$ & $1907 \pm 474$ & $2694 \pm 586$ \\
LVC, $\mathrm{mL}$ & $2532 \pm 595$ & $3688 \pm 736$ \\
FVC, $\mathrm{mL}$ & $2456 \pm 604$ & $3618 \pm 743$ \\
\hline
\end{tabular}

Abbreviations: $\mathrm{FEV}$, forced expiratory volume in one second; FVC, forced vital capacity; LVC, lung volume change.
Table 2 Distribution of subjects according to gender and age group, with data presented as $\mathrm{n}(\%)$

\begin{tabular}{lll}
\hline Age (years) & Females & Males \\
\hline All & $246(67.0)$ & $121(33.0)$ \\
$65-69$ & $77(31.3)$ & $35(28.9)$ \\
$70-74$ & $76(30.9)$ & $34(28.1)$ \\
$75-79$ & $50(20.3)$ & $22(18.2)$ \\
$\geq 80$ & $43(17.5)$ & $30(24.8)$ \\
\hline
\end{tabular}

aged $65-70$ years with a ratio below 0.70 was $11 \%$ (men $16 \%$, women $8 \%$ ); the proportion of subjects between 70 and 80 years of age with the ratio below 0.65 was $5 \%$ (men $12 \%$, women $2 \%$ ), whereas none of the subjects aged 80 years or more had $\mathrm{FEV}_{1} / \mathrm{FVC}<0.60$.

\section{Discussion}

This study provides additional evidence helpful for determining the most appropriate spirometric criteria to define airway obstruction in elderly subjects. The fifth percentile of $\mathrm{FEV}_{1} / \mathrm{FVC}$ observed in the considered sample of healthy subjects aged $>65$ years was lower than 0.70 in both men and women, thus confirming the inadequacy of this threshold for $\mathrm{FEV}_{1} / \mathrm{FVC}$ after the age of 65 years. Moreover, the findings of the present study suggest that, in such a population, $\mathrm{FEV}_{1} / \mathrm{FVC}<0.65$ and $<0.67$ (for males and females, respectively) could represent valid criteria that are simple to use and incorporate the known physiological decline in lung function with aging.

The present findings are in agreement with observations made by other authors, ${ }^{16-18}$ who have emphasized that the use of the $\mathrm{FEV}_{1} / \mathrm{FVC}$ threshold proposed by GOLD leads to a risk of overdiagnosis of COPD in geriatric subjects. Furthermore, the current results suggest that the inaccuracy of using a threshold of 0.70 for $\mathrm{FEV}_{1} / \mathrm{FVC}$ already exists in subjects aged 65 years and older. This differs to some extent from what has been suggested by the most recent GOLD guidelines ${ }^{11}$ (that recognize some imprecision of the threshold of 0.70 for $\mathrm{FEV}_{1} / \mathrm{FVC}$ in people over 70 years of age) and by Medbo et al, ${ }^{10}$ who suggested the use of a threshold of $\mathrm{FEV}_{1} / \mathrm{FVC}<0.65$ in subjects over the age of 70 years on the basis of prebronchodilator spirometry data from a population-based study in Norway.

Interestingly, in our study, the rate of decline in the $\mathrm{FEV}_{1} / \mathrm{FVC}$ ratio with aging was not statistically significant in men or women older than 65 years, because of a concomitant decline in both $\mathrm{FEV}_{1}$ and FVC. Thus, in contrast with the findings of Hardie et al, ${ }^{19}$ our results do not support the need to decrease the lower limit of normal for $\mathrm{FEV}_{1} / \mathrm{FVC}$ to 
Men

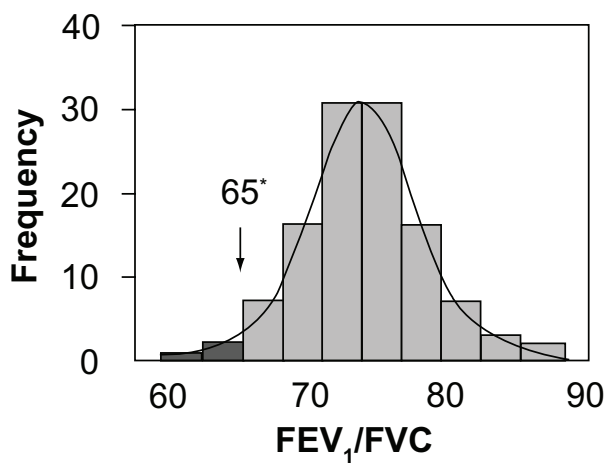

Women

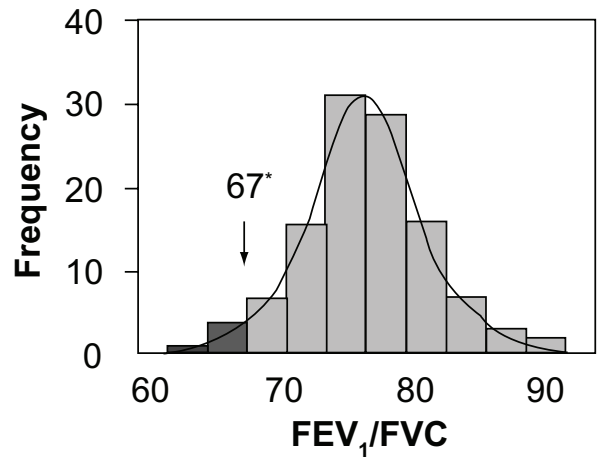

Figure I Distribution and fifth percentile of FEV,/FVC by gender (Caucasian Southern Europeans $>65$ years).

Note: Asterisks indicate the 5 th percentile.

Abbreviations: $\mathrm{FEV}_{1}$, forced expiratory volume in one second; FVC, forced vital capacity.

0.60 in elderly subjects ( $>80$ years). For the same reason, no predictive equation for $\mathrm{FEV}_{1} / \mathrm{FVC}$ could be derived; accordingly, the mean value and the fifth percentile of $\mathrm{FEV}_{1} / \mathrm{FVC}$ from this healthy population can be used as the predicted value and lower limit of normal, respectively, for people aged 65 years and over.

All reference equations derived from samples with a wide age range describe a progressive decline in the $\mathrm{FEV}_{1} / \mathrm{FVC}$ ratio with aging; the age-related decrease involves both $\mathrm{FEV}_{1}$ and $\mathrm{FVC}$, seems to be nonlinear, and accelerates with aging. ${ }^{30-32}$ In 1982, Crapo et $\mathrm{al}^{33}$ found that between 20 and 70 years of age, vital capacity decreases to approximately $75 \%$ of the best values achieved previously. According to the present observations, presumably in the oldest people the decline of vital capacity accelerates more than in the younger age groups and such a decline is similar to the reduction of $\mathrm{FEV}_{1}$, so that the $\mathrm{FEV}_{1} / \mathrm{FVC}$ ratio could undergo minimal variations in the last decades. Recently, Langhammer et $\mathrm{al}^{34}$ and Falaschetti et $\mathrm{al}^{35}$ observed that $\mathrm{FEV}_{1} / \mathrm{FVC}$ reaches a near plateau phase in elderly subjects. The authors emphasized that, although the sample consisted of subjects with a wide range of height and age, the extremes did not influence the equations.

In a reference study specifically designed for elderly residents in Madrid (age range 65-85 years), Garcia et al ${ }^{36}$ found a significant relationship between $\mathrm{FEV}_{1} / \mathrm{FVC}$ and age in men and between $\mathrm{FEV}_{1} / \mathrm{FVC}$, age and height in women. Even in this study, the predicted equation for $\mathrm{FEV}_{1} / \mathrm{FVC}$ had a very low $\mathrm{R}^{2}$ ( 0.048 and 0.083 for men and women, respectively) and the authors highlighted the strong negative relationship of FVC with age. By applying predictive equations recently derived from Kuster et $\mathrm{al}^{37}$ in a Swiss population, the lower limit of normal for $\mathrm{FEV}_{1} / \mathrm{FVC}$ does not show important decreases with aging; for example, in men with a height of $170 \mathrm{~cm}$, the lower limit of normal for $\mathrm{FEV}_{1} / \mathrm{FVC}$ ranges from 0.66 at the age of 65 years to 0.64 for people aged 95 years. All these results support a position in favor of almost stable predicted values and lower limits of normal for $\mathrm{FEV}_{1} / \mathrm{FVC}$ in elderly people aged 65 years and over.
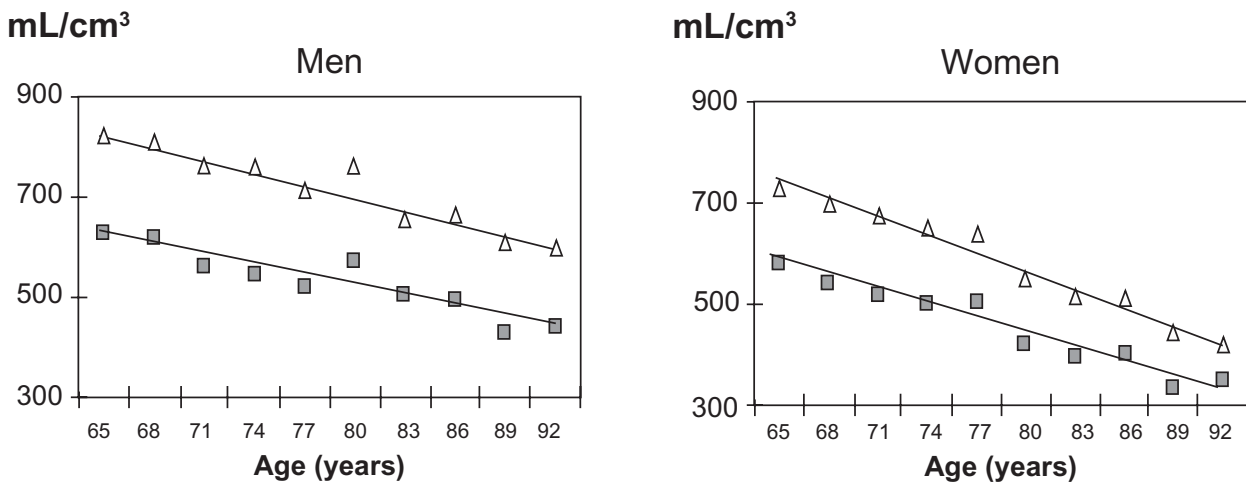

$\triangle$ FVC/height $^{3}$

$\mathrm{FEV}_{1}$ /height $^{3}$

Figure 2 Decline of FEV and FVC with aging, normalized for height. ${ }^{3}$

Abbreviations: $\mathrm{FEV}_{1}$, forced expiratory volume in one second; FVC, forced vital capacity. 
Table 3 Proportion of healthy elderly subjects with FEV /FVC ratio $<0.70$ in different age groups, with data presented as $n(\%)$

\begin{tabular}{llll}
\hline & \multicolumn{2}{l}{ Age (years) } \\
\cline { 2 - 4 } & $\begin{array}{l}\mathbf{6 5 - 7 9} \\
\mathbf{n}=\mathbf{2 9 4}\end{array}$ & $\begin{array}{l}\geq \mathbf{8 0} \\
\mathbf{n}=\mathbf{7 3}\end{array}$ & $\begin{array}{l}\text { All } \\
\mathbf{n}=\mathbf{3 6 7}\end{array}$ \\
\hline $\mathrm{FEV}, / \mathrm{FVC} \geq 0.70$ & $254(86)$ & $59(8 \mathrm{I})$ & $313(85)$ \\
$\mathrm{FEV}_{\mathrm{I}} / \mathrm{FVC}<0.70$ & $28(\mathrm{I})$ & $8(\mathrm{II})$ & $36(\mathrm{I0})$ \\
$\mathrm{FEV}, \% \geq 80$ & $12(4)$ & $6(8)$ & $18(5)$ \\
$\mathrm{FEV} / \mathrm{FVC}<0.70$ & $\mathrm{FEV} \%<80$ & &
\end{tabular}

Abbreviations: $\mathrm{FEV}_{1}$, forced expiratory volume in one second; $\mathrm{FVC}$, forced vital capacity.

A clear position in favor of the fixed threshold of $\mathrm{FEV}_{1} /$ FVC $<0.70$ has been recently reported by other authors, with the claim that it is easy to use, thus helping to remove barriers to widespread use of spirometry. ${ }^{3,6-8}$ Probably the use of the two lower fixed values for the elderly, suggested by data from the SARA study, does not add elements of particular complexity for physicians involved in interpretation of pulmonary function tests. However, this approach would diminish the number of false diagnoses of COPD, with significant cost savings due to reduction of inappropriately prescribed drugs. Thus, more resources could be redirected to primary prevention of COPD (smoking cessation) and treatment of more severe COPD.

Authors advocating retaining $\mathrm{FEV}_{1} / \mathrm{FVC}<0.70$ often quote the results of Mannino et al, who found that such a threshold is very good for identifying patients at risk of death and COPD-related hospitalizations. ${ }^{38}$ However, although this indicates that $\mathrm{FEV}_{1} / \mathrm{FVC}<0.70$ may recognize a proportion of individuals at risk, it does not mean that this is the best way to diagnose the disease. On the other hand, Vas Fragoso et $\mathrm{al}^{39}$ found elevated risk of death and respiratory symptoms in adults with $\mathrm{FEV}_{1} / \mathrm{FVC}$ less than the lower limit of normal. Sorino et $\mathrm{al}^{40}$ recently confirmed that $\mathrm{FEV}_{1} / \mathrm{FVC}$ less than the lower limit of normal, $\mathrm{FEV}_{1} / \mathrm{FEV}_{6}$ less than the lower limit of normal, and $\mathrm{FEV}_{1}$ less than the lower limit of normal are all significant predictors of allcause and cardiopulmonary mortality in older individuals. The strongest spirometric predictor of all-cause mortality remains the appropriately named vital capacity, because the majority of deaths in adult smokers, with or without COPD, are caused by cardiovascular disease.

Two recent studies investigated subjects in between the two definitions of airway obstruction (ie, $\mathrm{FEV}_{1} / \mathrm{FVC}<0.70$ but $\geq$ lower limit of normal), showing that their clinical profile is characterized by relevant comorbid disease and poor health-related quality of life, but similar exercise, frequency of exacerbations, and indices of systemic effects. ${ }^{41,42}$ The investigators emphasized that these subjects might be at risk and should be followed carefully; we should be aware that fewer than one in five smokers with mild airway obstruction ever develop clinically important COPD, and that today we are not yet able to identify which smokers will be rapid fallers. ${ }^{2,4}$

The present study has some limitations. First, the cohort was recruited for a cross-sectional investigation, whereas the effect of aging on respiratory function would be better assessed in a longitudinal study. It is plausible that $\mathrm{FEV} / \mathrm{FVC}$ decreases significantly even after the age of 65 years, but this can be less reliable when derived by a cross-sectional observation of older people. In fact, they could represent individuals who had higher spirometric values at a younger age, and $\mathrm{FEV}_{1} / \mathrm{FVC}$ similar to those of younger subjects at the time of recruitment. Second, subjects participating in the SARA project were not randomly selected from the population, but consisted mainly of subjects with nonrespiratory illnesses attending outpatient clinics; this might have resulted in some selection bias, although it would not explain the higher pulmonary volumes than in other studies. The authors wish to emphasize that $\mathrm{FEV}_{1} / \mathrm{FVC}$ less than the lower limit of normal should not be the only criterion used for diagnosis of airway obstruction, but should always be combined with evaluation of $\mathrm{FEV}_{1}$ as percent of predicted. Indeed, patients with severe airflow limitation could have an important reduction both in $\mathrm{FEV}_{1}$ and $\mathrm{FVC}$, with a sustained $\mathrm{FEV}_{1} / \mathrm{FVC}$ ratio. Thus, in doubtful cases, measurement of residual volume and total lung capacity is recommended.

In conclusion, the present findings confirm the inadequacy of $\mathrm{FEV}_{1} / \mathrm{FVC}<0.70$ for diagnosis of airway obstruction in elderly people, and we propose other easy to remember thresholds for $\mathrm{FEV}_{1} / \mathrm{FVC}$ after 65 years of age, ie, 0.65 in men and 0.67 women. Further studies are needed to assess both the classificatory and prognostic properties of such a threshold as well as epidemiological surveys to confirm it.

\section{Disclosure}

The authors report no conflicts of interest in this work.

\section{References}

1. Quanjer PH, Enright PL, Miller MR, et al. The need to change the method for defining mild airway obstruction. Eur Respir J. 2011;37: 720-722.

2. Enright $P$, Brusasco V. Counterpoint: Should we abandon $\mathrm{FEV}_{1} / \mathrm{FVC}<0.70$ to detect airway obstruction? Yes. Chest. 2010;138: 1040-1042.

3. Celli BR, Halbert RJ. Point: should we abandon $\mathrm{FEV}_{1} / \mathrm{FVC}<0.70$. No. Chest. 2010;138;1037-1040. 
4. Pellegrino R, Brusasco V, Viegi G, et al. Definition of COPD: based on evidence or opinion? Eur Respir J. 2008;31:681-690.

5. Enright PL. Are GOLDen slumbers drug induced? Am J Respir Crit Care Med. 2008;177:1291.

6. Fabbri LM, Boschetto P, Mapp CE. Time to wake up! Am J Respir Crit Care Med. 2008;177:1291-1292.

7. Fabbri LM. FEV ${ }_{1} / \mathrm{FVC}$ fixed ratio again! Chest. 2011;139:1252-1253.

8. Mannino DM. Defining chronic obstructive pulmonary disease ... and the elephant in the room. Eur Respir J. 2007;30:189-190.

9. Bhatt NY, Wood KL. What defines abnormal lung function in older adults with chronic obstructive pulmonary disease? Drugs Aging. 2008;25:717-728.

10. Medbo A, Melbye H. Lung function testing in the elderly - can we still use $\mathrm{FEV}_{1} / \mathrm{FVC}<70 \%$ as a criterion of COPD? Respir Med. 2007;101:1097-1105.

11. Global Initiative for Chronic Obstructive Lung Disease. Global Strategy for the Diagnosis, Management and Prevention of COPD, 2011. Available from: http://www.goldcopd.org/. Accessed May 20, 2012

12. Qaseem A, Wilt TJ, Weinberger SE, et al. American College of Physicians; American College of Chest Physicians; American Thoracic Society; European Respiratory Society. Diagnosis and management of stable chronic obstructive pulmonary disease: a clinical practice guideline update from the American College of Physicians, American College of Chest Physicians, American Thoracic Society, and European Respiratory Society. Ann Intern Med. 2011;155:179-191.

13. British Thoracic Society. BTS guidelines for the management of chronic obstructive pulmonary disease. Thorax. 2004;59 Suppl:1-232.

14. O’Donnell D, Aaron S, Bourbeau J, et al. Canadian Thoracic Society recommendations for management of chronic obstructive pulmonary disease: 2007 update. Can Respir J. 2007;14:5B-32B.

15. National Institute for Health and Clinical Excellence. Chronic obstructive pulmonary disease: management of chronic obstructive pulmonary disease in adults in primary and secondary care. National Clinical Guideline Centre, 2010. Available from: http:/guidance.nice.org.uk/ CG101/Guidance/pdf/English. Accessed June 27, 2011.

16. Hankinson JL, Odencrantz JR, Fedan KB. Spirometric reference values from a sample of the general US population. Am J Respir Crit Care Med. 1999;159:179-187.

17. Enright PL, Kronmal RA, Higgins M, et al. Spirometry reference values for women and men 65 to 85 years of age. Cardiovascular Health study. Am Rev Respir Dis. 1993;147:125-133.

18. Roberts SD, Farber MO, Knox KS, et al. $\mathrm{FEV}_{1} / \mathrm{FVC}$ ratio of $70 \%$ misclassifies patients with obstruction at the extremes of age. Chest. 2006;130:200-206.

19. Hardie JA, Buist AS, Vollmer WM, et al. Risk of over-diagnosis of COPD in asymptomatic elderly never-smokers. Eur Respir J. 2002;20: $1117-1122$.

20. Swanney MP, Ruppel G, Enright PL, et al. Using the lower limit of normal for the $\mathrm{FEV}_{1} / \mathrm{FVC}$ ratio reduces the misclassification of airway obstruction. Thorax. 2008;63:1046-1051.

21. Miller MR, Hankinson J, Brusasco V, et al. Standardisation of spirometry. Eur Respir J. 2005;26:319-338.

22. Pellegrino R, Viegi G, Brusasco V, et al. Interpretative strategies for lung function tests. Eur Respir J. 2005;26:948-968.

23. Bellia V, Pistelli R, Catalano F, et al. Quality control of spirometry in the elderly. The SARA study. SAlute Respiration nell'Anziano, Respiratory Health in the Elderly. Am J Respir Crit Care Med. 2000;161: 1094-1100.
24. American Thoracic Society. Standardization of spirometry, 1994 update. Am J Respir Crit Care Med. 1995;152:1107-1136.

25. Abramson MJ, Hensley MJ, Saunders NA, et al. Evaluation of a new asthma questionnaire. J Asthma. 1991;28:129-139.

26. Burney PG, Laitinen LA, Perdrizet S, et al. Validity and repeatability of the IUATLD (1984) Bronchial Symptoms Questionnaire: an international comparison. Eur Respir J. 1989;2:940-945.

27. Pistelli R, Bellia V, Catalano F, et al. Spirometry reference values for women and men aged 65-85 living in southern Europe: the effect of health outcomes. Respiration. 2003;70:484-489.

28. Peat JK, Woolcock AJ, Cullen K. Rate of decline of lung function in subjects with asthma. Eur J Respir Dis. 1987;70:171-179.

29. Cibella F, Cuttitta G, Bellia V, et al. Lung function decline in bronchial asthma. Chest. 2002;122:1944-1948.

30. Dockery DW, Ware JH, Ferris BG, et al. Distribution of forced expiratory volume in one second and forced vital capacity in healthy, white, adult never-smokers in six US cities. Am Rev Respir Dis. 1985; 131:511-520.

31. Glindmeyer HW, Lefante JJ, McColloster C, et al. Blue-collar normative spirometric values for Caucasian and African-American men and women aged 18 to 65. Am J Respir Crit Care Med. 1995;151: 412-422.

32. Brandli O, Schindler C, Kunzli N, et al. Lung function in healthy never smoking adults: reference values and lower limits of normal of a Swiss population. Thorax. 1996;51:277-283.

33. Crapo RO, Morris AH, Clayton PD, et al. Lung volumes in healthy nonsmoking adults. Bull Eur Physiopathol Respir. 1982;18: 419-425.

34. Langhammer A, Johnsen R, Gulsvik A, et al. Forced spirometry reference values for Norwegian adults: the Bronchial Obstruction in Nord-Trondelag Study. Eur Respir J. 2001;18:770-779.

35. Falaschetti E, Laiho J, Primatesta P, et al. Prediction equations for normal and low lung function from the Health Survey for England. Eur Respir J. 2004;23:456-463.

36. Garcia-Rio F, Pino JM, Dorgham A, et al. Spirometric reference equations for European females and males aged 65-85 years. Eur Respir J. 2004;24:397-405

37. Kuster SP, Kuster D, Schindler C, et al. Reference equations for lung function screening of healthy never-smoking adults aged $18-80$ years. Eur Respir J. 2008;31:860-868.

38. Mannino DM, Buist AS, Petty TL, et al. Lung function and mortality in the United States: data from the First National Health and Nutrition Examination Survey follow up study. Thorax. 2003;58: 388-393.

39. Vas Fragoso CA, Concato J, McAvay G, et al. The ratio of $\mathrm{FEV}_{1} / \mathrm{FVC}$ as a basis for establishing chronic obstructive pulmonary disease. $\mathrm{Am}$ J Respir Crit Care Med. 2010;181:446-451.

40. Sorino C, Sherrill D, Guerra S, et al. Prognostic value of $\mathrm{FEV}_{1} / \mathrm{FEV}_{6}$ in elderly people. Clin Physiol Funct Imaging. 2011;31:101-107.

41. Lamprecht B, Schirnhofer L, Kaiser B, et al. Subjects with discordant airways obstruction: lost between spirometric definitions of COPD. Pulm Med. 2011;2011:780215.

42. García-Rio F, Soriano JB, Miravitlles M, et al. Overdiagnosing subjects with COPD using the 0.7 fixed ratio: correlation with a poor healthrelated quality of life. Chest. 2011;139:1072-1080. 


\section{Appendix}

\section{Respiratory Health in the Elderly study group}

Coordinators: V Bellia (Palermo) and F Rengo (Napoli). Scientific committee members: R Antonelli Incalzi (Taranto), V Grassi (Brescia), S Maggi (Padua), G Masotti (Florence), G Melillo (Naples), D Olivieri (Parma), M Palleschi (Rome), R Pistelli (Rome), M Trabucchi (Rome), S Zuccaro (Rome).

Participating centers, principal investigator, and associated investigators (the latter in brackets): Divisione di Medicina I, Ospedale Geriatrici INRCA, Ancona, DL Consales (D Lo Nardo, P Paggi); Divisione di Geriatria, Ospedale Civile, Asti, F Goria (P Fea, G Iraldi, R Corradi); Cattedra di Gerontologia e Geriatria, Policlinico Universitario, Bari, A Capurso (R Flora, S Torres, G Venezia, M Mesto); Divisione di Geriatria, Ospedale Malpighi, Bologna, S Semeraro (L Bellotti, A Tansella); Divisione di Medicina Generale, Ospedale Civile, Brescia, V Grassi (S Cossi, G Guerini, C Fantoni, M De Martinis, L Pini); Clinica Pneumologica, Fondazione "E Maugeri", Telese, G Melillo (R Battiloro, C Gaudiosi, S De Angelis); Istituto di Medicina Interna e Geriatria, Ospedale Cannizzaro, Catania, L Motta (I Alessandria, S Savia); Istituto di Gerontologia e Geriatrici, Ospedale Ponte Nuovo, Università Florence, Florence, G Masotti (M Chiarlone, S Zacchei); Divisione di Geriatria, Ospedale Morgagni, Forli, V Pedone (D Angelini, D Cilla); Divisione di Geriatria, Ospedale Galliera, Genova, E Palummeri (M Agretti, P Costelli, D Torriglia); Grouppo Ricerca Geriatrica Ricerca
Geriatrica, Ospedale Richiedei, Gussago, M Trabucchi (P Barbisoni, F Guerini, P Ranieri); Divisione di Geriatria, Ospedale Generale, L'Aquila, F Caione (D Caione, M La Chiara); Divisione di Geriatria, Ospedale San Gerardo, Monza, G Galetti (A Cantatore, D Casarotti, G Anni); Cattedra di Gerontologia e Geriatria, Università Federico II, Napoli, F Rengo (F Cacciatore, AI Pisacreta, C Calabrese); Istituto di Medicina Interna, Ospedale Geriatrico, Padova, G Enzi (P Dalla Montà, S Peruzza, P Albanese, F Tiozzo); Istituto di Clinica delle Malattie dell'Apparato Respiratorio, Ospedale Rasori, Parma, D Olivieri (V Bocchino, A Comel, N Barbarito); Istituto di Gerontologia e Geriatria, Policlinico Monteluce, Perugia, U Senin (F Arnone, L Camilli, S Peretti); Divisione di Geriatria, Ospedale Israelitico, Roma, SM Zuccaro (M Marchetti, L Palleschi); Divisione di Geriatria, Ospedale Generale Addolorata, Roma, M Palleschi (C Cieri, F Vetta); Istituto di Medicina Interna e Geriatria, Policlinico Gemelli, Roma, PU Carbonin (F Pagano, P Ranieri); Istituto di Semeiotica Medicina e Geriatria, Policlinico Le Scotte, Siena, S Forconi (G Abate, G Marotta, E Pagni); Fondazione San Raffaele, Cittadella della Carità, Taranto, R Antonelli-Incalzi (C Imperiale, C Spada); Cattedra di Gerontologia e Geriatria, Ospedale Maggiore, Milano, C Vergani (G Giardini, MC Sandrini, I Dallera); Cattedra di Malattie dell'Apparato Respiratorio, Ospedale V Cervello, Palermo, V Bellia (F Catalano, N Scichilone, S Battaglia).

Coordinating center: Dipartimento di Medicina, Pneumologia, Fisiologia e Nutrizione Umana, Università degli Studi di Palermo.
International Journal of COPD

\section{Publish your work in this journal}

The International Journal of COPD is an international, peer-reviewed journal of therapeutics and pharmacology focusing on concise rapid reporting of clinical studies and reviews in COPD. Special focus is given to the pathophysiological processes underlying the disease, intervention programs, patient focused education, and self management protocols.

\section{Dovepress}

This journal is indexed on PubMed Central, MedLine and CAS. The manuscript management system is completely online and includes a very quick and fair peer-review system, which is all easy to use. Visit http://www.dovepress.com/testimonials.php to read real quotes from published authors. 